\title{
Pemanfaatan internet untuk edukasi gizi bagi penyandang diabetes mellitus
}

The utilization of internet for nutrition education by patients with diabetes mellitus

Emyr Reisha Isaura ${ }^{1}$, Probosuseno ${ }^{2}$, Muhammad Primiaji Rialihanto ${ }^{3}$

\begin{abstract}
Background: The pattern of disease incidence has changed nowadays as indicated from epidemiological transition, from infection to non infection diseases or non communicable diseases. Quantity of diabetes mellitus (DM) patients in Indonesia is increasing every year. Integrated management of DM requires synergy from different parties. According to Act No. 36/2009 on Health, article 17 paragraph 1 states that the government is responsible for availability of access to information, education, and health facilities to improve and maintain highest health status. Objective: The study aimed to analyze the utilization of internet or online media in the dissemination of recommended eating pattern and physical activities of DM patients as prevention against complication. Method: The study used cross-sectional design and was carried out in January 2013 at Surabaya Municipality. It used e-survey, with secondary data from hospitals at Surabaya Municipality. Samples were DM patients of 20-50 years old registered in hospitals and agrred with informed consent. Samples were taken purposively involving 66 respondents. Results: There was difference in eating pattern between DM patients utilizing online and those using non online media (OR=3.33; CI 95\%=1.06-10.43; $p=0.03)$; and in physical activities $(O R=0.09 ; C I 95 \%=0.01-0.75 ; p=0.008)$. Conclusion: The utilization of online media affected eating pattern and physical activity pattern in DM patient as much as 3.33 times and 0.09 times greater than in those not using online media in looking for communication, information, and education resources in supporting prevention against DM complication. Thus online media could be one of effective and efficient methods in the delivery of communication, information, and education for DM patients by health staff.
\end{abstract}

KEY WORDS: eating pattern, physical activities, DM patients, internet, online media, nutrition education

\begin{abstract}
ABSTRAK
Latar belakang: Saat ini, pola kejadian penyakit telah mengalami perubahan yang ditandai dengan transisi epidemiologi, yaitu perubahan pola yang semula didominasi oleh penyakit infeksi beralih ke penyakit non-infeksi atau penyakit tidak menular. Peningkatan jumlah penyandang diabetes mellitus (DM) di Indonesia tinggi setiap tahunnya. Penatalaksanaan DM secara terpadu membutuhkan sinergi dari berbagai pihak. Sesuai dengan UU RI Nomor 36 tahun 2009 tentang kesehatan, pasal 17 ayat 1 menyebutkan bahwa pemerintah bertanggungjawab atas ketersediaan akses terhadap informasi, edukasi, dan fasilitas pelayanan kesehatan untuk meningkatkan dan memelihara derajat kesehatan yang setinggi-tingginya. Tujuan: Mempelajari pemanfaatan internet atau media online dalam penyampaian anjuran pola makan dan aktivitas fisik pada penyandang DM sebagai pencegahan terhadap komplikasi. Metode: Desain penelitian cross-sectional dan dilaksanakan pada bulan Januari tahun 2013 di Kota Surabaya. Penelitian ini dilaksanakan menggunakan e-survey dengan data sekunder dari rumah sakit di Kota Surabaya. Sampel adalah penyandang DM usia 20-50 tahun, terdaftar di rumah sakit, dan menyetujui informed consent. Sampel diambil secara purposive sampling dengan total sampel 66 responden. Hasil: Terdapat perbedaan pola makan penyandang DM yang memanfaatkan media online dan non-online $(\mathrm{OR}=3,33$; CI 95\%=1,06-10,43; $\mathrm{p}=0,03)$, demikian pula pada pola aktivitas fisiknya $(\mathrm{OR}=0,09 ; \mathrm{CI}$ $95 \%=0,01-0,75 ; p=0,008)$. Simpulan: Pemanfaatan media berpengaruh pada perubahan pola makan dan pola aktivitas fisik bagi penyandang DM berturut-turut sebesar 3,33 kali dan 0,09 kali dibandingkan penyandang DM yang tidak memanfaatkan media online dalam pencarian sumber komunikasi, informasi, dan edukasi (KIE) untuk menunjang pencegahan terhadap komplikasi penyakitnya. Media online dapat menjadi salah satu mode yang efektif dan efisien dalam penyampaian KIE bagi penyandang DM oleh petugas kesehatan.
\end{abstract}

KATA KUNCI: pola makan, aktivitas fisik, edukasi gizi, diabetes, internet

\section{PENDAHULUAN}

Undang-undang Republik Indonesia (UU RI) nomor 36 tahun 2009 tentang kesehatan, pasal 17 ayat 1 menyebutkan bahwa pemerintah bertanggungjawab

\footnotetext{
${ }^{1}$ Korespondensi: Jl. Terusan Cikampek No. 9A, Malang, Jawa Timur, e-mail: emyr.reisha@gmail.com

2 Bagian Penyakit Dalam, Rumah Sakit Umum Pusat Dr. Sardjito, Jl. Kesehatan No.1, Yogyakarta 55281

3 Politeknik Kesehatan Kementerian Kesehatan Yogyakarta Jurusan Gizi, J1. Tata Bumi No.3 Banyuraden, Gamping, Sleman Yogyakarta 55293
} 
atas ketersediaan akses terhadap informasi, edukasi, dan fasilitas pelayanan kesehatan untuk meningkatkan dan memelihara derajat kesehatan yang setinggi-tingginya. Pelayanan kesehatan itu hendaklah merata bagi semua lapisan masyarakat dengan berbagai pola penyakit. Pola kejadian penyakit mengalami perubahan ditandai dengan transisi epidemiologi, yaitu perubahan pola penyakit dan kematian yang semula didominasi oleh penyakit infeksi beralih ke penyakit noninfeksi atau penyakit tidak menular (non communicable disease). Perubahan pola penyakit sangat dipengaruhi oleh keadaan demografi (umur, jenis kelamin, pendidikan), sosial ekonomi (tingkat pendapatan), dan sosial budaya (adat istiadat). Diabetes mellitus (DM) merupakan salah satu penyakit tidak menular kronis yang paling umum di hampir semua negara dan terus meningkat dalam jumlah yang signifikan. Pembangunan ekonomi dan urbanisasi telah mendorong ke arah perubahan gaya hidup yang ditandai dengan berkurangnya aktivitas fisik dan meningkatnya obesitas $(1,2)$.

Berdasarkan laporan Federasi Diabetes Internasional (IDF), Indonesia menempati urutan kesepuluh peringkat teratas negara yang memiliki jumlah penderita diabetes terbanyak di dunia dengan jumlah penyandang DM sebanyak 7,3 juta orang pada tahun 2011 dan diperkirakan akan mencapai 11,8 juta jiwa pada tahun 2030 (3). Prevalensi DM di Indonesia menunjukkan angka yang sangat tinggi sehingga dibutuhkan sinergi dari semua sektor kesehatan dan masyarakat. Media komunikasi antar kalangan menjadi kunci utama penyebaran informasi dari satu pihak ke pihak yang lainnya. Bagi semua penyandang DM, harus selalu mengontrol penyakitnya untuk mencegah kemungkinan timbulnya komplikasi. Kontrol yang baik adalah setiap hari, bahkan setiap saat karena glukosa darah harus selalu dipertahankan dalam batas normal. Internet dan world wide web (WWW) juga dapat digunakan oleh individu untuk menyesuaikan pesan pendidikan gizi melalui penyesuaian sistem otomatis sebaik konseling gizi pribadi dengan jarak jauh (4).

Penyandang DM yang secara aktif mencari informasi kesehatan khususnya tentang edukasi gizi, dapat mengurangi dan menunjang kendala ketidakpatuhan dalam mematuhi pola makan dan aktivitas fisik yang seharusnya dilakukan. Perubahan pola makan dan perilaku tersebut membutuhkan suatu cara yang dapat dilakukan oleh ahli gizi dalam mendampingi dan memantau sekaligus sebagai sarana edukasi pasien. Pemantauan dan pendampingan serta edukasi tersebut dapat dilakukan dengan menggunakan salah satu sarana media informasi teknologi yaitu melalui internet. Oleh karena itu, diharapkan kelompok yang memanfaatkan edukasi gizi melalui internet atau media online memiliki pola makan dan pola aktivitas fisik yang lebih baik jika dibandingkan dengan kelompok yang memanfaatkan edukasi gizi melalui media non-online dalam hal pencegahan komplikasi pada penyandang DM. Berdasarkan latar belakang tersebut, maka perlu dipelajari lebih lanjut mengenai proses komunikasi, informasi, dan edukasi (KIE) yaitu pemanfaatan edukasi gizi melalui internet atau media online sebagai langkah pencegahan terhadap komplikasi bagi penyandang DM.

\section{BAHAN DAN METODE}

Berdasarkan jenis survei analitik, penelitian ini tergolong sebagai survei cross-sectional. Waktu penelitian untuk pengumpulan data dilakukan selama 1 bulan yaitu pada bulan Januari 2013. Sebagai populasi, unit pengamatan dan analisis adalah pasien yang tercatat di instalasi rawat jalan sebagai penderita DM tipe 2 di Rumah Sakit Angkatan Laut (RSAL) dr. Ramelan dan Rumah Sakit Umum Daerah (RSUD) dr. Soetomo Surabaya. Pengambilan sampel secara purposive sampling yang dipilih berdasarkan kriteria inklusi dan eksklusi. Kriteria inklusi adalah penyandang DM yang tercatat di Instalasi Rawat Jalan RSAL dr. Ramelan dan RSUD dr. Soetomo Surabaya yang dinyatakan positif DM minimal 3 bulan sebelum tanggal penelitian dilaksanakan; berdomisili di Kota Surabaya dan memiliki nomor telepon yang dapat dihubungi; bersedia ikut serta dalam penelitian dan menandatangani informed consent; pernah mendapat konseling gizi dari pihak rumah sakit; berusia 20-55 tahun. Kriteria eksklusinya adalah subjek sedang hamil dan menyusui atau subjek sedang menjalani rawat inap di rumah sakit. Pasien yang ditetapkan sebagai sampel adalah pasien yang selama periode waktu yang ditentukan mengikuti prosedur penelitian hingga selesai. 
Data pasien yang tercatat sejak Agustus 2012 dari dua RS tersebut sebanyak 7547 orang kemudian dipilih yang sesuai kriteria diperoleh sebanyak 302 orang. Peneliti mulai menghubungi nomor yang terdata dan sebanyak 115 orang yang menyatakan bersedia mengikuti penelitian tetapi hingga saat penelitian berakhir hanya diperoleh sejumlah 66 orang responden. Hal tersebut karena pasien keluar dari penelitian dan tidak dapat dihubungi kembali hingga waktu pengumpulan data yang ditentukan selesai. Karakteristik responden meliputi riwayat keluarga dengan DM yang dilihat dari ada atau tidaknya keluarga yang menderita DM; tipe DM dan lama pasien sebagai diabetisi berdasarkan diagnosis dokter yang dikelompokkan menjadi DM tipe 1 atau 2 serta lama diagnosis kurang dari 3 tahun atau lebih dari 3 tahun; dan indeks massa tubuh (IMT=berat badan dibagi kuadrat tinggi badan) pasien dikategorikan menjadi status gizi normal (IMT $\left.=18-23 \mathrm{~kg} / \mathrm{m}^{2}\right)$ dan lebih $\left(>23 \mathrm{~kg} / \mathrm{m}^{2}\right)$.

Pola makan dan aktivitas fisik merupakan variabel terikat (dependent variable) sedangkan pemanfaatan media merupakan variabel bebas (independent variable). Pola makan adalah pola sebaran asupan karbohidrat yang dikonsumsi penyandang DM yang diketahui dengan menggunakan form recall $3 \times 24$ jam secara acak dengan salah satu hari adalah akhir pekan atau hari libur yang dikumpulkan secara e-mail dan phoned survey. Pola makan dikatakan baik apabila sebaran asupan karbohidrat merata dan kurang baik apabila sebaran asupan karbohidrat tidak merata $(5,6)$. Data pola makan penyandang DM yang terkumpul dikategorikan berdasarkan jenis makanan sumber karbohidrat (beras, mie, kentang, ketela pohon, tepung-tepungan), jumlah makanan, dan frekuensi makannya. Berdasarkan jenis dan jumlah makanan tersebut dilihat konversi makanan dengan asupan satuan penukar karbohidrat. Perhitungan satuan penukar makanan tersebut berbentuk angka lalu dilihat konsistensi jumlahnya pada $3 \times 24$ jam, angka tersebut akan membentuk suatu pola. Pola yang merata dan teratur merupakan pola makan yang baik. Apabila pola makan tidak teratur dengan sebaran jumlah asupan tidak merata dikategorikan tidak baik.

Data aktivitas fisik yang terkumpul dikategorikan berdasarkan kriteria lama waktu melakukan aktivitas olahraga dalam seharinya selama 1 minggu, yaitu baik apabila dilakukan lebih dari $30 \mathrm{menit} / \mathrm{hari}$ dengan frekuensi lebih dari atau sama dengan 3 kali per minggu sedangkan dikategorikan kurang baik apabila dilakukan kurang dari 30 menit/hari dan atau lebih dari 30 menit/ hari dengan frekuensi kurang dari 3 kali per minggu (7). Pemanfaatan media adalah penggunaan media sebagai sarana edukasi bagi penyandang DM yang ditanyakan dengan kuesioner untuk mengetahui apakah pasien memanfaatkan media online atau media non-online. Memanfaatkan media online bila pernah mengakses informasi tentang DM melalui internet dan memanfaatkan media non-online bila tidak pernah mengakses informasi tentang DM melalui internet. Data pemanfaatan media tersebut dikategorikan berdasarkan sumber, alat yang digunakan, lokasi responden dalam mengakses informasi, dan frekuensi penggunaan serta lama mengakses.

Data penelitian dikumpulkan melalui prosedur berikut: data nama yang didapat dari dua rumah sakit tersebut setelah melalui proses seleksi berdasarkan kriteria inklusi dan eksklusi kemudian dihubungi menggunakan telepon, diberikan penjelasan tentang prosedur penelitian, menanyakan informed consent, jika menyetujuinya maka dilanjutkan ke tahap pengumpulan data. Prosedur tersebut dilakukan mulai saat pertama kali menghubungi daftar calon responden, apabila setelah 5 kali dihubungi tidak bisa maka tidak diikutkan dalam penelitian. Responden yang ikut dalam penelitian diberikan pertanyaan melalui telepon dan jika mau memberikan alamat e-mail maka peneliti akan mengirimkan kuesioner tersebut melalui e-mail. Kuesioner tersebut terdiri dari 4 bagian, bagian pertama adalah berisi pertanyaan yang berhubungan dengan karakteristik responden termasuk menanyakan tentang apakah responden telah mendapatkan konseling dari pihak rumah sakit sebagai salah satu kriteria inklusi dalam penelitian ini, bagian kedua adalah pertanyaan tentang pemanfaatan media, bagian ketiga adalah pertanyaan tentang pola aktivitas fisik, dan bagian terakhir yang ditanyakan sebanyak 3 kali yaitu pencatatan makan secara random sebanyak $3 \times 24$ jam dengan 1 hari libur atau akhir pekan (Sabtu, Minggu). Data yang terkumpul dianalisis menggunakan analisis Chi-Square dengan menggunakan $\alpha=0,05$. Data juga dianalisis untuk melihat seberapa besar pengaruhnya menggunakan nilai odds ratio (OR). 


\section{HASIL}

Hasil penelitian ini berisi tentang bagaimana masyarakat Indonesia khususnya di daerah perkotaan yang diwakilkan oleh Kota Surabaya dalam memanfaatkan fasilitas yang telah tersedia untuk menunjang kemandiriannya memenuhi kebutuhan KIE yang berkaitan dengan penyakit DM. Sejumlah 66 pasien yang terdiri dari 27 orang pria dan 39 orang wanita dapat dilihat karakteristiknya pada Tabel 1. Mayoritas

Tabel 1. Pemanfaatan media menurut karakteristik responden

\begin{tabular}{|c|c|c|c|c|c|c|}
\hline \multirow{3}{*}{ Variabel } & \multicolumn{6}{|c|}{ Pemanfaatan media } \\
\hline & \multicolumn{2}{|c|}{$\begin{array}{c}\text { Online } \\
\left(\mathrm{n}_{1}=36\right)\end{array}$} & \multicolumn{2}{|c|}{$\begin{array}{c}\text { Non-online } \\
\left(\mathrm{n}_{2}=\mathbf{3 0}\right)\end{array}$} & \multicolumn{2}{|c|}{$\begin{array}{c}\text { Total } \\
(\mathrm{n}=66)\end{array}$} \\
\hline & $\mathbf{n}_{1}$ & $\%$ & $\mathrm{n}_{2}$ & $\%$ & $\mathbf{n}$ & $\%$ \\
\hline \multicolumn{7}{|l|}{ Jenis kelamin } \\
\hline Pria & 12 & 33 & 15 & 50 & 27 & 41 \\
\hline Wanita & 24 & 67 & 15 & 50 & 39 & 59 \\
\hline \multicolumn{7}{|l|}{ Usia (tahun) } \\
\hline$\leq 30$ & 12 & 33 & 1 & 3 & 13 & 20 \\
\hline $31-40$ & 5 & 14 & 4 & 13 & 9 & 14 \\
\hline $41-50$ & 14 & 39 & 15 & 50 & 29 & 44 \\
\hline$>50$ & 5 & 14 & 10 & 33 & 15 & 23 \\
\hline \multicolumn{7}{|l|}{ Pekerjaan } \\
\hline Karyawan & 10 & 28 & 7 & 23 & 17 & 26 \\
\hline TNI/POLRI & 14 & 39 & 15 & 50 & 29 & 44 \\
\hline Wiraswasta & 6 & 17 & 8 & 27 & 14 & 21 \\
\hline Tidak bekerja & 6 & 17 & 0 & 0 & 6 & 9 \\
\hline \multicolumn{7}{|l|}{ Tingkat pendidikan } \\
\hline SD & 1 & 3 & 6 & 20 & 7 & 11 \\
\hline SLTP & 5 & 14 & 1 & 3 & 6 & 9 \\
\hline SLTA & 17 & 47 & 19 & 63 & 36 & 55 \\
\hline PT & 13 & 36 & 4 & 13 & 17 & 26 \\
\hline \multicolumn{7}{|l|}{ Status pernikahan } \\
\hline Menikah & 24 & 67 & 29 & 97 & 53 & 80 \\
\hline Belum menikah & 12 & 33 & 1 & 3 & 13 & 20 \\
\hline \multicolumn{7}{|l|}{ IMT $\left(\mathrm{kg} / \mathrm{m}^{2}\right)$} \\
\hline $18-23$ & 18 & 50 & 7 & 23 & 25 & 38 \\
\hline$>23$ & 18 & 50 & 23 & 77 & 41 & 62 \\
\hline \multicolumn{7}{|l|}{ Riwayat keluarga } \\
\hline Ada & 21 & 58 & 21 & 70 & 42 & 64 \\
\hline Tidak ada & 15 & 42 & 9 & 30 & 24 & 36 \\
\hline \multicolumn{7}{|l|}{ Tipe DM } \\
\hline Tipe 1 & 2 & 6 & 1 & 3 & 3 & 5 \\
\hline Tipe 2 & 34 & 94 & 29 & 97 & 63 & 95 \\
\hline \multicolumn{7}{|c|}{ Lama diagnosis (tahun) } \\
\hline$\leq 3$ & 26 & 72 & 6 & 20 & 32 & 48 \\
\hline$>3$ & 10 & 28 & 24 & 80 & 34 & 52 \\
\hline
\end{tabular}

subjek penelitian adalah wanita (59\%), usia berada pada kisaran 41-50 tahun (44\%), bekerja sebagai TNI/POLRI (44\%), tingkat pendidikan Sekolah Lanjutan Tingkat Atas (SLTA) (55\%), dan sudah menikah (80\%). Berdasarkan IMT, subjek masih banyak yang berada pada status gizi lebih (62\%) dan memiliki riwayat keluarga dengan DM (64\%).

Perubahan dalam jenis adalah mengganti gula pasir menjadi gula diit pada makanan dan minuman yang dikonsumsi. Perubahan jumlah yaitu selalu menghitung jumlah karbohidrat yang dikonsumsi setiap waktu makan. Perubahan jadwal adalah konsistensi jumlah satuan karbohidrat dalam setiap waktu makan selama tiga hari acak dengan salah satunya adalah hari libur. Responden yang memanfaatkan media online cenderung lebih banyak (32\%) yang melakukan perubahan pola makan secara menyeluruh (jenis, jumlah, jadwal) daripada yang melakukan perubahan pola makan dalam hal jenis dan jadwalnya (12\%) atau jenis dan jumlahnya (11\%). Sebaliknya, responden penyandang DM yang memanfaatkan media non-online justru lebih banyak konsisten melakukan perubahan pola makan dalam hal jenis dan jumlahnya saja (30\%) (Tabel 2). Hal ini mengindikasikan bahwa responden yang memanfaatkan media online memiliki pola makan yang lebih baik dibandingkan dengan responden yang memanfaatkan media non-online.

Hal tersebut didukung oleh hasil yang menunjukkan bahwa penyandang DM yang memanfaatkan media internet (online) dengan pola makan baik adalah sebanyak 30 responden dari total 36 responden yang memanfaatkan media online. Hal ini menunjukkan bahwa pemanfaatan media berhubungan signifikan dengan pola makan penyandang $\mathrm{DM}(\mathrm{p}=0,034)$. Berdasarkan nilai $\mathrm{OR}=3,33$ dapat dinyatakan bahwa kemungkinan risiko penyandang DM untuk melakukan perubahan pola makan yang tidak baik semakin rendah dengan memanfaatkan media internet (online) (Tabel 3). Pola makan penyandang DM dalam setiap kali makan adalah 3 kali makan utama, 2-3 kali makan selingan, dan diharapkan adanya konsistensi pada jumlah, jadwal, dan jenis makanan.

Alat komunikasi dapat ditemukan baik di tempat bekerja maupun di tempat tinggal, sebagaimana kelebihan media ini yaitu dapat digunakan kapan dan dimanapun. 
Tabel 2. Perubahan pola makan menurut pemanfaatan media

\begin{tabular}{lcccccc}
\hline \multirow{2}{*}{$\begin{array}{c}\text { Perubahan } \\
\text { pola makan }\end{array}$} & $\begin{array}{c}\text { Online } \\
\left(\mathrm{n}_{1}=\mathbf{3 6}\right)\end{array}$ & $\begin{array}{c}\text { Non-online } \\
\left(\mathrm{n}_{2}=\mathbf{3 0}\right)\end{array}$ & $\begin{array}{c}\text { Total } \\
(\mathbf{n}=\mathbf{6 6})\end{array}$ \\
\cline { 2 - 7 } & $\mathbf{n}_{1}$ & $\mathbf{\%}$ & $\mathbf{n}_{2}$ & $\mathbf{\%}$ & $\mathbf{n}$ & $\mathbf{\%}$ \\
\hline Jenis dan jumlah & 7 & 11 & 20 & 30 & 27 & 41 \\
Jenis dan jadwal & 8 & 12 & 0 & 0 & 8 & 12 \\
Jenis, jumlah, dan jadwal & 21 & 32 & 10 & 15 & 31 & 47 \\
\hline
\end{tabular}

Tabel 3. Pola makan berdasarkan pemanfaatan media

\begin{tabular}{|c|c|c|c|c|c|c|c|c|c|c|}
\hline \multirow{3}{*}{$\begin{array}{c}\text { Pemanfaatan } \\
\text { media }\end{array}$} & \multicolumn{5}{|c|}{ Pola makan } & \multirow{3}{*}{$\chi^{2}$} & \multirow{3}{*}{$\mathbf{p}$} & \multirow{3}{*}{ OR } & \multirow{2}{*}{\multicolumn{2}{|c|}{ CI 95\% }} \\
\hline & \multicolumn{2}{|c|}{ Baik } & \multicolumn{2}{|c|}{ Tidak baik } & \multirow{2}{*}{$\begin{array}{c}\text { Total } \\
\mathbf{n}\end{array}$} & & & & & \\
\hline & $\mathbf{n}$ & $\%$ & $\mathbf{n}$ & $\%$ & & & & & Lower & Upper \\
\hline Online $\left(\mathrm{n}_{1}=36\right)$ & 30 & 63 & 6 & 33 & 36 & & 034 & & & \\
\hline Non-online $\left(\mathrm{n}_{2}=30\right)$ & 18 & 37 & 12 & 67 & 30 & 4,49 & 0,034 & 3,33 & 1,06 & 10,43 \\
\hline Total $(n=66)$ & 48 & 100 & 18 & 100 & 66 & & & & & \\
\hline
\end{tabular}

Alat yang digunakan bisa berupa alat portable seperti laptop, notebook, smartphone, tablet, atau alat stable yaitu berupa packet computer (PC) yang tidak dapat dipindahpindahkan. Penyandang DM yang memanfaatkan media internet dengan pola makan yang baik sebagian besar memanfaatkan layanan online yang disediakan oleh pemerintah (33\%), melalui situs sosial online berupa blog $(43 \%)$, dan diakses dari tempat bekerjanya $(47 \%)$. Proporsi terbesar akses internet dilakukan secara rutin minimal 1 kali per bulan (37\%) dengan menggunakan alat akses berupa stable (63\%). Sumber informasi bagi penyandang DM selain diperoleh secara online juga berasal dari sumber non-online. Sumber informasi nononline bagi penyandang DM sebagian besar diperoleh dari sumber buku, media massa, dan dari sesama diabetisi yang mencapai 50\% dari penyandang DM yang memiliki pola makan yang baik (Tabel 4). Hal ini menggambarkan keragaman media online dan non-online yang tersedia dan bisa dimanfaatkan oleh para penyandang diabetes untuk melakukan pengawasan dan pengontrolan diri agar tidak sampai terjadi komplikasi.

Seluruh responden dalam penelitian ini melakukan aktivitas olahraga, tetapi berbeda dalam intensitas dan frekuensi per minggunya. Sebagian besar responden (83\%) penyandang DM melakukan aktivitas olahraga sebanyak 3 kali atau lebih selama satu minggu. Sementara sisanya (17\%) melakukan aktivitas fisik kurang dari 3 kali per minggu. Apabila frekuensi aktivitas tersebut ditinjau berdasarkan pemanfaatan media oleh penyandang DM, maka menunjukkan bahwa proporsi penyandang DM yang memanfaatkan media online dengan frekuensi aktivitas yang memenuhi syarat minimal ( $\geq 3$ kali) (39\%), jumlahnya lebih rendah dibandingkan dengan kelompok responden yang memanfaatkan media non-online (44\%). Namun, perbedaan tersebut relatif kecil.

Penyandang DM yang memanfaatkan media internet (online) dengan pola aktivitas baik (47\%), proporsinya lebih rendah dibandingkan penyandang DM yang memanfaatkan media non-online (53\%) dan secara statistik hubungan antara pemanfaatan media dengan perubahan pola aktivitas fisik adalah signifikan $(\mathrm{p}=0,008)$ (Tabel 5). Dengan demikian, dapat dinyatakan bahwa ada hubungan yang bermakna antara pemanfaatan media dengan perubahan pola aktivitas fisik yang dilakukan oleh penyandang DM. Berdasarkan nilai OR dapat diketahui bahwa kemungkinan risiko penyandang DM semakin rendah (0,09 kali) untuk melakukan perubahan pola aktivitas fisik yang tidak baik dengan memanfaatkan media online yang tersedia. Akan tetapi, hal ini tidak memiliki kontribusi terhadap praktisnya dalam hal pemanfaatan media terhadap pola aktivitas fisik.

Fasilitas ini telah tersedia dengan bentuk media internet dengan beberapa kelebihan dan kekurangan, serta bentuk cetaknya yang juga dengan beberapa kelebihan dan kekurangannya. Masyarakat hanya butuh memilih dan menggunakan fasiltas yang tersedia dengan secerdas mungkin untuk mengupayakan kemandirian penyandang DM dalam hal pengawasan 
Emyr Reisha Isaura, dkk: Pemanfaatan internet untuk edukasi gizi bagi penyandang diabetes mellitus

Tabel 4. Persentase pola makan menurut variabel media

\begin{tabular}{|c|c|c|c|c|}
\hline \multirow{3}{*}{ Variabel } & \multicolumn{4}{|c|}{ Pola makan } \\
\hline & \multicolumn{2}{|c|}{ Baik } & \multicolumn{2}{|c|}{ Tidak baik } \\
\hline & $\mathbf{n}$ & $\%$ & $\mathbf{n}$ & $\%$ \\
\hline \multicolumn{5}{|l|}{ Penyedia layanan online $(\mathrm{n}=36)$} \\
\hline Institusi resmi pemerintah & 10 & 33,3 & 3 & 50,0 \\
\hline Lembaga sosial (non-pemerintah) & 9 & 30,0 & 1 & 16,7 \\
\hline Lembaga swasta profit (non-pemerintah) & 5 & 16,7 & 2 & 33,3 \\
\hline Lembaga terkait produk DM (non-pemerintah) & 6 & 20,0 & 0 & 0,0 \\
\hline \multicolumn{5}{|l|}{ Situs sosial online $(\mathrm{n}=36)$} \\
\hline Blog & 13 & 43,3 & 3 & 50,0 \\
\hline E-mail grup & 5 & 16,7 & 0 & 0,0 \\
\hline Facebook & 4 & 13,3 & 1 & 16,7 \\
\hline Website grup & 8 & 26,7 & 2 & 33,4 \\
\hline \multicolumn{5}{|l|}{ Lokasi akses online $(\mathrm{n}=36)$} \\
\hline Tempat bekerja & 14 & 46,7 & 3 & 50,0 \\
\hline Tempat tinggal & 7 & 23,3 & 1 & 16,7 \\
\hline Tempat bekerja+tempat tinggal & 9 & 30,0 & 2 & 33,3 \\
\hline \multicolumn{5}{|l|}{ Kerutinan akses online $(\mathrm{n}=36)$} \\
\hline 1x per hari & 4 & 13,3 & 0 & 0,0 \\
\hline$>1 \mathrm{x}$ per hari & 3 & 10,0 & 1 & 16,7 \\
\hline $1 \mathrm{x}$ per minggu & 3 & 10,0 & 2 & 33,3 \\
\hline$>1 \mathrm{x}$ per minggu & 1 & 3,3 & 0 & 0,0 \\
\hline $1 \mathrm{x}$ per bulan & 11 & 36,7 & 2 & 33,3 \\
\hline$>1 \mathrm{x}$ per bulan & 8 & 26,7 & 1 & 16,7 \\
\hline \multicolumn{5}{|l|}{ Alat akses online $(\mathrm{n}=36)$} \\
\hline Portable & 11 & 36,7 & 1 & 16,7 \\
\hline Stable & 19 & 63,3 & 5 & 83,3 \\
\hline \multicolumn{5}{|l|}{ Sumber non-online $(\mathrm{n}=66)$} \\
\hline Buku & 7 & 14,6 & 1 & 5,6 \\
\hline Leaflet, booklet & 10 & 20,8 & 5 & 27,8 \\
\hline Media massa (koran, majalah) & 7 & 14,6 & 6 & 33,3 \\
\hline $\mathrm{Buku}+$ media massa + sesama diabetisi & 24 & 50,0 & 6 & 33,3 \\
\hline
\end{tabular}

Tabel 5. Pola aktivitas fisik berdasarkan pemanfaatan media

\begin{tabular}{|c|c|c|c|c|c|c|c|c|c|c|}
\hline \multirow{3}{*}{$\begin{array}{c}\text { Pemanfaatan } \\
\text { media }\end{array}$} & \multicolumn{5}{|c|}{ Pola aktivitas fisik } & \multirow{3}{*}{$\chi^{2}$} & \multirow{3}{*}{$\mathbf{p}$} & \multirow{3}{*}{ OR } & \multirow{2}{*}{\multicolumn{2}{|c|}{ CI 95\% }} \\
\hline & \multicolumn{2}{|c|}{ Baik } & \multicolumn{2}{|c|}{ Tidak baik } & \multirow{2}{*}{$\frac{\text { Total }}{n}$} & & & & & \\
\hline & $\mathbf{n}$ & $\%$ & $\mathbf{n}$ & $\%$ & & & & & Lower & Upper \\
\hline Online $\left(\mathrm{n}_{1}=36\right)$ & 26 & 47 & 10 & 91 & 36 & & 0008 & & & 074 \\
\hline Non-online $\left(\mathrm{n}_{2}=30\right)$ & 29 & 53 & 1 & 9 & 30 & 7,04 & 0,008 & 0,09 & 0,01 & 0,14 \\
\hline Total $(n=66)$ & 55 & 100 & 11 & 100 & 66 & & & & & \\
\hline
\end{tabular}

dan pengontrolan diri agar tidak sampai jatuh dalam kondisi komplikasi ataupun kronis. Beberapa hal yang dapat mendasari pemilihan responden untuk menggunakan media KIE adalah kelebihan dan kekurangan yang nampak. Media internet memiliki beberapa kelebihan yaitu lebih privasi, memiliki kesempatan berdiskusi dengan penyedia layanan maupun sesama penyandang DM, mudah dilakukan, biaya yang dikeluarkan sedikit atau murah, informasi yang tersedia lengkap, memiliki kebaruan dalam menyediakan informasi (up-to-date), bisa dilakukan dan didapatkan kapanpun dan dimanapun.

Berkaitan dengan UU RI tentang kesehatan, tanggung jawab pemerintah ini belum sepenuhnya 
Emyr Reisha Isaura, dkk: Pemanfaatan internet untuk edukasi gizi bagi penyandang diabetes mellitus

Tabel 6. Persentase pola aktivitas fisik menurut variabel media

\begin{tabular}{|c|c|c|c|c|}
\hline \multirow{3}{*}{ Variabel } & \multicolumn{4}{|c|}{ Pola aktivitas fisik } \\
\hline & \multicolumn{2}{|c|}{ Baik } & \multicolumn{2}{|c|}{ Tidak baik } \\
\hline & $\mathbf{n}$ & $\%$ & n & $\%$ \\
\hline \multicolumn{5}{|l|}{ Penyedia layanan online $(\mathrm{n}=36)$} \\
\hline Institusi resmi pemerintah & 11 & 42 & 2 & 20 \\
\hline Lembaga sosial (non-pemerintah) & 4 & 16 & 6 & 60 \\
\hline Lembaga swasta profit (non-pemerintah) & 5 & 19 & 2 & 20 \\
\hline Lembaga terkait produk DM (non-pemerintah) & 6 & 23 & 0 & 0 \\
\hline \multicolumn{5}{|l|}{ Situs sosial online $(\mathrm{n}=36)$} \\
\hline $\mathrm{B} \log$ & 12 & 46 & 4 & 40 \\
\hline E-mail grup & 3 & 12 & 2 & 20 \\
\hline Facebook & 3 & 12 & 2 & 20 \\
\hline Website grup & 8 & 30 & 2 & 20 \\
\hline \multicolumn{5}{|l|}{ Lokasi akses online $(\mathrm{n}=36)$} \\
\hline Tempat bekerja & 14 & 54 & 3 & 30 \\
\hline Tempat tinggal & 5 & 19 & 3 & 30 \\
\hline Tempat bekerja + tempat tinggal & 7 & 27 & 4 & 40 \\
\hline \multicolumn{5}{|l|}{ Kerutinan akses online $(n=36)$} \\
\hline 1x per hari & 4 & 15 & 0 & 0 \\
\hline$>1 \mathrm{x}$ per hari & 4 & 15 & 0 & 0 \\
\hline $1 \mathrm{x}$ per minggu & 3 & 12 & 2 & 20 \\
\hline$>1 \mathrm{x}$ per minggu & 1 & 4 & 0 & 0 \\
\hline 1x per bulan & 10 & 39 & 3 & 30 \\
\hline$>1 \mathrm{x}$ per bulan & 4 & 15 & 5 & 50 \\
\hline \multicolumn{5}{|l|}{ Alat akses online $(\mathrm{n}=36)$} \\
\hline Portable & 8 & 31 & 4 & 40 \\
\hline Stable & 18 & 69 & 6 & 60 \\
\hline \multicolumn{5}{|l|}{ Sumber non-online $(\mathrm{n}=66)$} \\
\hline Buku & 7 & 13 & 1 & 9 \\
\hline Leaflet, booklet & 14 & 25 & 1 & 9 \\
\hline Media massa (koran, majalah) & 11 & 20 & 2 & 18 \\
\hline $\mathrm{Buku}+$ media massa + sesama diabetisi & 23 & 42 & 7 & 64 \\
\hline
\end{tabular}

terlaksana dengan baik. Terbukti dengan adanya masyarakat yang lebih memilih untuk mencari informasi dari penyedia layanan non-pemerintah. Hal ini tidak lepas dari keterbatasan yang dimiliki pemerintah.

Tabel 6 menunjukkan bahwa penyandang DM yang memanfaatkan media internet dengan pola aktivitas fisik baik, lebih memilih penyedia layanan online dari institusi resmi pemerintah ( $42 \%$ ) dan melalui situs sosial online berupa blog $(46 \%)$ yang diakses melalui tempat kerjanya (54\%). Akses internet pada umumnya minimal 1 kali per bulan (39\%) dengan menggunakan alat akses online berbentuk stable (69\%). Sementara itu, sumber non-online sebagian besar ( $42 \%$ ) berasal dari buku, media massa, dan sesama penyandang diabetes.

\section{BAHASAN}

Pemanfaatan internet atau media online dalam penyampaian anjuran pola makan dan aktivitas fisik pada penyandang DM ini efektif karena kebutuhan pasien akan informasi yang berkaitan dengan DM telah tersedia. Efisiensi juga tercapai karena internet ini dapat digunakan kapan dan dimanapun serta oleh siapapun. Diabetes tipe 2 akhir-akhir ini telah menjadi suatu krisis global yang juga mengancam perekonomian suatu negara, terutama bagi negara-negara berkembang. Hal itu terjadi disebabkan oleh banyak hal misalnya urbanisasi, transisi pola makan, dan meningkatnya pola hidup sedentari, yang juga berparalel dengan tumbuh suburnya angka obesitas di seluruh dunia begitu pula di Indonesia. Beberapa faktor 
yang berkontribusi pada akselerasi epidemi diabetes di negara-negara Asia termasuk Indonesia yaitu angka IMT di atas $23 \mathrm{~kg} / \mathrm{m}^{2}$, tingginya konsumsi karbohidrat olahan dalam waktu makan (contoh: nasi putih), serta menurunnya level aktivitas fisik yang dramatis. Meskipun demikian, interaksi antara pola makan dan gaya hidup kebarat-baratan dan latar belakang genetik dapat mempercepat pertumbuhan diabetes dalam konteks transisi gizi yang cepat. Studi epidemiologi dan uji klinis acak menunjukkan bahwa diabetes tipe 2 ini sebagian besar dapat dicegah melalui diit dan modifikasi pola aktivitas fisik (8).

Penelitian lainnya juga menyatakan bahwa wanita berusia di atas 40 tahun berisiko lebih tinggi untuk menjadi obesitas dan akhirnya diabetes karena pola aktivitas wanita menjadi lebih rendah, terutama bila sama-sama memiliki riwayat keluarga dengan DM akibat pola makan tidak baik atau tidak sehat (9). Hal tersebut sesuai dengan penelitian ini yang mendapatkan bahwa mayoritas responden adalah wanita (59\%) dengan rerata usia 41-50 tahun dan IMT lebih dari $23 \mathrm{~kg} / \mathrm{m}^{2}$. Responden dalam penelitian ini terdapat 63 orang dengan DM tipe 2 dan mayoritas memiliki riwayat keluarga dengan penyakit yang sama.

Penggunaan internet membantu orang dengan penyakit kronis beserta keluarganya dalam mengakses berbagai sumber informasi dengan mudah untuk membangun keahlian manajemen diri atau kemandirian dan menemukan dukungan psikososial (10). Masyarakat hanya butuh memilih dan menggunakan fasilitas yang tersedia dengan secerdas mungkin untuk mengupayakan kemandirian penyandang DM dalam hal pengawasan dan pengontrolan diri agar tidak sampai jatuh dalam kondisi komplikasi ataupun kronis. Perubahan pola makan penyandang DM pada penelitian ini difokuskan pada prinsip diit DM yaitu tepat jenis, tepat jumlah, dan tepat jadwal (3J). Sebagai contoh, perubahan dalam penggunaan gula pasir biasa menjadi gula diit; konsistensi seorang penyandang DM dalam mengonsumsi karbohidrat untuk setiap kali waktu makan; menjaga kestabilan gula darah dalam tubuh agar penyandang DM tidak sampai pada kondisi kekurangan. Jadwal yang dianjurkan adalah 3 kali makan utama dengan 2 kali makan selingan dan setiap waktu makan minimal mengonsumsi satu penukar karbohidrat.
Tingkat kesehatan dan biaya pengelolaan DM tipe 2 dapat sangat dipengaruhi oleh manajemen diri (self-management). Hasil penelitian di Australia menunjukkan secara sederhana tentang efektivitas intervensi bantuan komputer dalam tujuan meningkatan aktivitas fisik. Menetapkan tujuan yang berkaitan dengan self-management perilaku mungkin tidak perlu didikte atau difasilitasi oleh seorang dokter atau staf klinik. Namun, banyak waktu dan usaha yang dapat diakomodasi melalui teknologi komputer interaktif (11). Penggunaan internet ini juga dipengaruhi oleh kefasihan berbahasa Inggris yang merupakan pendorong utama penggunaan internet. Selain itu, tingkat pendidikan dan keadaan sosial ekonomi juga menjadi gradien yang kuat dalam penggunaan internet. Akses broadband yang lebih umum di kalangan orang dewasa muda, dalam rumah tangga dengan status sosial ekonomi lebih tinggi, dan di daerah perkotaan atau pinggiran kota (12).

Penelitian ini menunjukkan bahwa pemanfaatan internet sebagai pendukung sumber informasi, berdampak positif bagi adanya motivasi perubahan pola makan dan pola aktivitas fisik terutama olahraga. Apabila masyarakat mau dan turut aktif dalam memanfaatkan fasilitas internet maka informasi kesehatan akan selalu tersedia dan banyak kemudahan yang diperoleh daripada harus bergantung pada petugas kesehatan. Penyandang DM khususnya, akan dapat mengelola diri dimanapun berada sehingga dapat menjadi mandiri di kemudian hari. Selain dapat berinteraksi langsung dengan petugas kesehatan sebaik bertemu langsung menggunakan media yang tersedia, penyandang DM juga dapat berkomunikasi dengan seluruh penyandang DM di dunia melalui grup atau percakapan dan tulisan pengalamannya. Ada beberapa kendala yang menjadi hambatan dalam berkomunikasi dengan penyandang DM di belahan dunia lain, salah satunya adalah kendala bahasa. Dari beberapa situs informasi kesehatan yang tersedia, mayoritas berbahasa Inggris dan disediakan secara lengkap oleh orang yang berada di negara lain.

Bagi banyak orang, internet berfungsi sebagai sumber akses terhadap informasi kesehatan dimanapun berada. Menyangkut kualitas variabel internet berbasis informasi kesehatan, mungkin dapat memberikan dukungan tambahan untuk gagasan bahwa bidang 
internet adalah posisi yang baik untuk intervensi kesehatan masyarakat (13). Kombinasi dari jangkauan potensi yang tinggi dan efikasi menunjukkan beberapa kemungkinan kelebihan intervensi internet dibandingkan dengan modalitas lainnya (14). Sesuai dengan penelitian ini bahwa penyandang DM akan melalui perubahan pola makan dan aktivitas fisik dalam waktu yang tidak singkat ditunjukkan dengan responden yang melakukan perubahan pola makan yang didukung oleh pemanfaatan internet hanya sebesar $32 \%$. Waktu yang diperlukan untuk melakukan perubahan sejak awal diagnosis, mayoritas adalah lebih dari 1 tahun. Perubahan yang telah dilakukan dalam pola makan DM adalah pada jenis, jumlah, dan jadwal makan.

Perubahan pola makan pada responden penelitian ini menunjukkan perbedaan yang signifikan yaitu penyandang DM yang memanfaatkan media online dalam hal KIE memiliki pola makan yang lebih baik daripada penyandang DM yang tidak memanfaatkan media online. Kendala bahasa menjadi salah satu faktor yang membuat pengguna internet khususnya pencari informasi kesehatan kesulitan mendapatkan informasi yang lengkap. Pada saat mencari sumber informasi kesehatan (terutama DM) yang lengkap, up-to-date, dan terpercaya, hanya sedikit sumber yang menyediakannya bahkan pada penyedia layanan yang resmi maupun swasta tidak selalu memperbarui informasinya. Salah satu contoh situs dari persatuan yang spesifik pada satu jenis penyakit di Indonesia yang tidak dapat diakses, yang semestinya menjadi salah satu situs yang dapat memberikan informasi yang selalu baru dan dapat diakses kapan dan dimanapun. Demikian pula dengan situs bagi pelayanan diabetes di salah satu rumah sakit di Jawa Timur yang terakhir memperbarui informasi tentang DM pada tahun 2009. Masih kurangnya partisipasi tenaga kesehatan dalam penyediaan informasi yang berkualitas tersebut menjadi salah satu faktor para penyandang DM tidak lagi memanfaatkan internet sebagai sumber KIE.

Keadaan tersebut bertentangan dengan hasil penelitian sebelumnya di Amerika Serikat bahwa manajemen diri berbasis intervensi internet tampaknya cukup sukses. Studi diabetes konsisten dengan studi terbaru yang melibatkan populasi pasien lain menunjukkan bahwa secara singkat, komputer berbasis intervensi interaktif dapat menghasilkan perbaikan yang signifikan dan relatif jangka panjang dalam perilaku diit (15). Penyediaan informasi dasar diabetes sebaik sebuah pendampingan personal dan manajemen diri melalui internet terbukti dapat dilakukan (feasible). Intervensi dari internet yang sudah tervalidasi membuktikan bahwa dapat menjadi sumber berharga yang mengatasi hambatan biaya dan manajemen diabetes konvensional lainnya (16). Internet memang menawarkan akses yang luas ke informasi kesehatan dan keuntungan dari interaktivitas, penyesuaian informasi, dan anonimitas. Namun, masih terkendala oleh akses yang tidak merata dan kendala penggunaan dengan tantangan navigasi akibat banyak fitur desain (misalnya disorganisasi, bahasa teknis, dan kurangnya permanen). Konsep komunikasi baik interpersonal maupun massa dapat membuka jalan untuk penyelidikan dan memahami pengaruh internet pada keyakinan kesehatan dan perilaku, pelayanan kesehatan, hasil medis, dan sistem perawatan kesehatan (17).

Penelitian ini melihat sisi pola aktivitas fisik dari intensitas dan frekuensi responden dalam melakukan olahraga. Diperoleh bahwa semua responden melakukan olahraga, tetapi berbeda dari intensitas dan frekuensinya dalam seminggu. Hasilnya sebanyak $83 \%$ responden melakukan olahraga sebanyak 3 kali atau lebih selama satu minggu. Informasi yang tersedia di internet mengenai olahraga bagi penyandang DM, baik itu berupa senam maupun ajakan untuk melakukan olahraga minimal 3 kali seminggu telah sesuai dengan anjuran tenaga kesehatan. Manfaat aktivitas fisik dapat membantu penderita diabetes mencapai berbagai tujuan, termasuk meningkatkan kebugaran kardiorespirasi, peningkatan kekuatan, memperbaiki kontrol glikemik penurunan resistensi insulin, memperbaiki peningkatan profil lipid, dan pemeliharaan berat badan. Penurunan berat badan bagi penyandang DM dengan status gizi berlebih dapat dilakukan dengan efektif dibantu oleh pemanfaatan internet (18).

Penyandang DM harus diberitahu bahwa olahraga teratur merupakan bagian penting dari rencana pengobatan. Sebuah program latihan yang tepat harus dilakukan secara individual untuk memenuhi kebutuhan masing-masing pasien. Sebagai contoh, pada pasien dengan neuropati diabetes adalah menghindari banyak 
berjalan sedangkan orang dengan diabetik retinopati tidak diperbolehkan latihan beban. Selain itu, latihanlatihan harus direncanakan sesuai dengan usia, tingkat pendidikan, pengalaman sebelumnya, dan kebiasaan aktivitas fisik pasien. Hipoglikemia, hiperglikemia, memburuknya penyakit jantung, dan komplikasi dari penyakit adalah risiko utama selama program latihan yang tidak aman. Dalam rangka meminimalkan risiko dan memilih intensitas yang tepat dari program, pasien harus menjalani pemeriksaan medis lengkap sebelum memulai latihan termasuk pemeriksaan penuh dari sistem kardiovaskular (19). Sebelum memulai program aktivitas fisik yang lebih intens dari berjalan, penderita diabetes harus dinilai untuk kondisi yang mungkin kontraindikasi pada beberapa jenis olahraga, predisposisi cedera atau dikaitkan dengan kemungkinan peningkatan penyakit kardiovaskular (CVD) (20). Didukung pula dengan intensitas aktivitas fisik yang sedang seperti jalan cepat selama minimal 150 menit per minggu juga memberikan peranan penting dalam mengurangi risiko diabetes, bahkan tanpa adanya penurunan berat badan (21).

\section{SIMPULAN DAN SARAN}

Kelompok yang memanfaatkan edukasi gizi melalui media online mempunyai pola makan yang lebih baik daripada kelompok yang memanfaatkan edukasi gizi melalui media non-online. Dalam artian, pemanfaatan internet mempunyai dampak atau hubungan positif yang signifikan terhadap perubahan pola makan penyandang DM sebesar 3,33 kali lebih baik daripada yang tidak memanfaatkan media online. Demikian juga pemanfaatan internet mempunyai hubungan positif yang signifikan terhadap perubahan pola aktivitas fisik penyandang DM. Media online dapat menjadi salah satu moda yang efektif dan efisien dalam hal penyampaian KIE bagi penyandang DM oleh petugas kesehatan. Pemandirian penyandang DM dapat dilakukan dengan memanfaatkan media baik online maupun non-online, terutama media online sebaik pendampingan secara tatap muka.

Perlu pengembangan sistem edukasi bagi penyandang DM dengan memanfaatkan media online oleh tenaga kesehatan khususnya ahli gizi supaya mendayagunakan sumber daya di instansi untuk mengelola situs yang berisi informasi kesehatan bagi masyarakat agar dapat beroperasi sesuai dengan tujuan dan fungsinya. Perlu upaya mempromosikan media online yang dimiliki oleh institusi resmi pemerintah di bidang kesehatan untuk dapat mengajak dan memudahkan masyarakat secara mandiri dalam pencarian sumber KIE. Perlu diteliti lebih lanjut tentang kualitas informasi kesehatan yang tersedia oleh instansi di bidang kesehatan yang memiliki situs resmi dengan pencapaian tujuan dan manfaat bagi masyarakat khususnya klien di instansi tersebut. Penelitian lebih lanjut terkait dengan lokasi yang lebih luas dan karakteristik responden yang spesifik, menggunakan metode serta analisis data yang lebih dalam untuk melihat faktor-faktor khusus lain yang mempengaruhi pola makan dan pola aktivitas fisik penyandang DM.

\section{RUJUKAN}

1. Whiting DR, Guariguata L, Weil C, Shaw J. IDF diabetes atlas: global estimates of the prevalence of diabetes for 2011 and 2030. Diabetes Res Clin Pract [series online] 2011 Dec [cited 2012 Jul 25];94(3):311-21. Available from: URL: http.//www.ncbi.nlm.nih.gov/pubmed/22079683

2. Guariguata L, Whiting D, Weil C, Unwin N. The International Diabetes Federation diabetes atlas methodology for estimating global and national prevalence of diabetes in adults. Diabetes Res Clin Pract [series online] 2011 Dec [cited $2012 \mathrm{Jul}$ 25];94(3):322-32. Available from: URL: http.//dx.doi.org/10.1016/j.diabres.2011.10.040

3. Unwin N, Gan D, Whiting D. The IDF Diabetes Atlas: providing evidence, raising awareness and promoting action. Diabetes Res Clin Pract [series online] 2010 Jan [cited 2011 Jun 24];87(1):2-3. Available from: URL: http.// www.ncbi.nlm.nih.gov/pubmed/19962207

4. Brug J, Oenema A, Campbell M. Past, present, and future of computer-tailored nutrition education. Am J Clin Nutr 2003;77(4 Suppl):1028-34.

5. Abate N, Chandalia M. Ethnicity, type 2 diabetes \& migrant asian indians. Indian J Med Res 2007;125(3):251-8.

6. Shi Z, Hu X, Yuan B, Hu G, Pan X, Dai Y, HolmboeOttesen G, Byles J. Association between food patterns and metabolic syndrome in China. Journal of Diabetology 2010;2(3):1-12.

7. Singh M, Chakravarty A, Gupta KK, Agrawal NK. Food consumption pattern of non-communicable disease patients. Indian J Prev Soc Med 2010;41(3\&4):143-7.

8. Hu FB. Globalization of diabetes: the role of diet, lifestyle, and genes. Diabetes care [series online] 2011 Jun [cited 2011 Sep 20];34(6):1249-57. Available 
from: URL: http.//www.ncbi.nlm.nih.gov/pmc/articles/ PMC3114340/?tool=pmcentrez

9. Hu FB, Li TY, Colditz GA, Willett WC, Manson JE. Television watching and other sedentary behaviors in relation to risk of obesity and type 2 diabetes mellitus in women. JAMA [series online] $2003 \mathrm{Apr}$ [cited $2011 \mathrm{Sep}$ 20];289(14):1785-91. Available from: URL: http.//jama. jamanetwork.com/article.aspx?articleid $=196345$

10. Zrebiec JF, Jacobson AM. What attracts patients with diabetes to an internet support group? a 21-month longitudinal website study. Diabet Med [series online] 2001 Feb [cited 2011 Sep 20];18(2):154-8. Available from: URL: http:.//www.ncbi.nlm.nih.gov/pubmed/11251681

11. McKay HG, King D, Eakin EG, Seeley JR, Glasgow RE. The diabetes network internet-based physical activity intervention: a randomized pilot study. Diabetes Care [series online] 2001 Aug [cited 2013 Feb 24];24(8):1328$34[24$ screens]. Available from: URL: http.//www.care. diabetesjournals.org/content/24/8/1328.short

12. Bennett GG, Glasgow RE. The delivery of public health interventions via the internet: actualizing their potential. Annu Rev Public Health [series online] 2009 Apr [cited 2011 Jul 7];30:273-92. Available from: URL: http.// www.annualreviews.org/doi/full/10.1146/annurev. publhealth.031308.100235?url_ver=Z39.88-2003\&rfr_ id $=$ ori:rid:crossref.org\&rfr_dat $=$ cr_pub\%3dpubmed \&

13. Eysenbach G, Powell J, Kuss O, Sa ER. Empirical studies assessing the quality of health information for consumers on the world wide web: a systematic review. JAMA [series online] 2002 May [cited 2011 Jul 7];287(20):2691-700. Available from: URL: http.//jama.jamanetwork.com/ article.aspx?articleid=194953

14. Glasgow RE, McKay HG, Piette JD, Reynolds KD. The RE-AIM framework for evaluating interventions: what can it tell us about approaches to chronic illness management? Patient Educ Couns [series online] 2001 Aug [cited 2011 Jul 7];44(2):119-27. Available from: URL: http.//www. ncbi.nlm.nih.gov/pubmed/11479052

15. Glasgow RE, Boles SM, McKay HG, Feil EG, Barrera M Jr. The D-Net diabetes self-management program: long- term implementation, outcomes, and generalization results. Prev Med [series online] 2003 Apr [cited 2013 Feb 24];36(4):410-9. Available from: URL: http.// knowledgetranslation.ca/sysrev/articles/project21/Ref ID 3203-20090628223930.pdf

16. McKay HG, Glasgow RE, Feil EG, Boles SM, Barrera M Jr. Internet-based diabetes self-management and support: initial outcomes from the diabetes network project. Rehabilitation Psychology [series online] 2002 Feb [cited 2013 Feb 24];47(1):31-48. Available from: URL: http.//psycnet.apa.org/journals/rep/47/1/31/

17. Cline RJW, Haynes KM. Consumer health information seeking on the internet: the state of the art. Health Educ Res 2001;16(6):671-92.

18. Wing RR, Goldstein MG, Acton KJ, Birch LL, Jakicic JM, Sallis JF Jr, Smith-West D, Jeffery RW, Surwit RS. Behavioral science research in diabetes: lifestyle changes related to obesity, eating behavior, and physical activity. Diabetes Care [series online] 2001 Jan [cited 2013 Feb 24];24(1):117-23. Available from: URL: http.//care.diabetesjournals.org/content/24/1/117.full. pdf + html

19. Polikandrioti M, Dokoutsidou H, Hospital E. The role of exercise and nutrition in type II diabetes mellitus management. Health Sci J 2009;3(4):216-21.

20. Klein S, Sheard NF, Pi-Sunyer X, Daly A, Wylie-Rosett J, Kulkarni K, Clark NG. Weight management through lifestyle modification for the prevention and management of type 2 diabetes: rationale and strategies: a statement of the American Diabetes Association, the North American Association for the Study of Obesity, and the American Society for Clinical Nutrition. Diabetes Care [series online] 2004 Aug [cited 2013 Feb 24];27(8):2067-73. Available from: URL: http.//care.diabetesjournals.org/ content/27/8/2067.full.pdf + html

21. Ahmad LA, Crandall JP. Type 2 diabetes prevention: a review. Clinical Diabetes [series online] 2010 March [cited 2013 Feb 24];28(2):53-9. Available from: URL: http.//clinical.diabetesjournals.org/cgi/doi/10.2337/ diaclin.28.2.53 